\title{
Analysis of the organizational climate assess- ment on the example of employees of the textile industry
}

\author{
Jacek Grodzicki ${ }^{1, *}$, and Bożena Kłusek-Wojciszke ${ }^{1}$ \\ ${ }^{1}$ University of Gdańsk, Faculty of Economics, 119/121 Armii Krajowej St., 81-824 Sopot, Poland
}

\begin{abstract}
Harmonization of the relationship between society, economy, and nature requires both the development of more environmentally friendly technologies or restrictions on its exploitation, as well as a change in the way of life and work. This is particularly about improving the quality of work to reduce energy consumption and/or pollution. In this context, the issue of the organizational climate that determines job satisfaction and increasing cooperation towards sustainable development is of particular importance. The article presents the results of research on the organizational climate carried out on a selected group of students employed in textile industry enterprises. The analysis of the results allows us to state the high assessment of the climate at work in its individual spheres and a high level of trust in the management of the organization.
\end{abstract}

\section{Introduction}

When we analyzing the concept of Sustainable Development, it can be noted that it concerns both environmental protection, the quality of human life, and methods of further economic growth. It assumes the occurrence of interdependencies between such areas as nature, society and the economy [1]. This means a far-reaching interdisciplinary approach to research on socio-economic development. This approach to relations between people, the environment, and the economy allows them to find a common space and interdependencies in them [2]. Appropriate management of these areas is to ensure well-being associated with such qualities as happiness, harmony, fulfillment or community [3].

For this to happen it is necessary to raise ecological awareness, and with it change the way of life and the hierarchy of values. Hence, the work environment is more and more often paid attention.

One of the spheres that have an impact on shaping awareness of social responsibility for the surrounding environment and activities undertaken in this area is the organizational climate.

\footnotetext{
${ }^{*}$ Corresponding author: jacek.grodzicki@ug.edu.pl
} 
Research on it goes back to the work of Kurt Lewin conducted in the 1950s [4,5]. This concept became especially popular in the sixties and seventies of the twentieth century, along with the publication of the book by Litwin and Stringer [6]. This interest in social relations at work contributed to the detection of the correlation between job satisfaction and productivity and the organizational climate $[7,8,9]$.

Trying to define this concept, many researchers refer to Forhand and Gilmer [10], who noticed that the organizational climate is a set of features that describe the organization and differenciate organizations among themselves. It is relatively durable and has an impact on the behavior of people in the organization. In turn, Guion [11] maintained that the climate concerns both the attributes of the organization and the perception of the individual, and that it is simply an alternative to affective reactions to the organization, such as job satisfaction. Similarly, Taguiri, defining the organizational climate, stated that it is a relatively persistent quality of the internal environment of the organization experienced by its members, affects their behavior and can be described by values and sets of attributes of the organization " [12]. It follows that it is a collection of measurable properties (dimensions) of the work environment that people in this environment perceive directly or indirectly and that affect their motivation and behavior [13].

The current measurement of the organizational climate should focus on this perception of the workplace and assessment of its impact on motivation and behavior during organizational and environmental changes [12]. Analyzing various proposals regarding this concept, it seems that most of them agree that it covers three levels of behavior, namely: individual, interpersonal and organizational [7, 14, 15, 16].

It is good to remember that the behavior of employees is shaped by the constant changes caused by the processes of the transformation of the organization. Such phenomena as: globalization, mergers and acquisitions, outsourcing, reorganization, etc. affect both the perception of the organization itself and the motivation and commitment of employees [17, $18]$.

\section{Dimentions of the Organization Climate}

An important element of the debate on climate research concerns not so much a way of measuring, but rather what to measure. There are many proposals regarding organizational dimensions that should be included in such analyzes. Generally, it is believed that there are eight basic dimentions of organizational (psychological) climate [19]:

- Autonomy (The perception of self-determination with respect to work procedures, goals and priorities).

- Cohesion (The perception of togetherness or sharing within the organisation setting, including the willingness of members to provide support).

- Trust (The perception of freedom to communicate openly with members at higher organisational levels about sensitive or personal issues).

- Pressure (The perception of time demands with respect to task completion and performance standards).

- Support (The perception of tolerance of member behaviour by superiors).

- Recognition (The perception that members' contributions to the organisation are acknowledged).

- Fairness (The perception that organisational practices are equitable and non-arbitrary).

- Innovation (The perception that change and creativity are encouraged).

A wide analysis of the proposed areas allowed to conclude that the organizational dimensions at the formal level are: structure, policy, objectives, management practices, task specialization, decision making, standards and rewards. At the informal level, the organiza- 
tional climate refers to the identity, needs of employees, responsibility, communication, information exchange, support or conflict resolution [16]. As part of such designated areas, several research questionnaires were built. We considered two models of organizational climate that have been proposed in the literature. Tustin [20] suggested that the following dimensions represent common elements of organizational climate:

- interpersonal communication,

- support and relationship in the work group,

- risk and challenge (the feeling that risks and challenges exist in the work and that knowledge and abilities are utilized and developed),

- promotion and pay system (the feeling that promotion depends on good performance and the fairness of the pay policy),

- identification (the feeling that an employee belongs to an organisation and is loyal to the organisation),

- standards (the perceived importance of implicit goals and performance standards),

- recognition and reward (the feeling that recognition and reward are given in return for good performance),

- participation (the feeling that the supervisor has confidence in the subordinate's ability to participate in decision-making),

- training and development (the feeling that training and development takes place and that it achieves results),

- responsibility (sense of independence in choosing work methods).

And a research questionnaire developed by Martins [21], which is based on such dimensions as:

-mission and goals (employees' perception of and satisfaction with the organisation's strategic focus and mission and goals),

- technology (employees satisfaction with the support systems),

- task systems (various activities and actions that influence work activities),

- management processes (managerial functions that influence employees),

- interpersonal and social processes (the perceptions of rewards, relationships, respect and support that prevail within a team),

- external environment (employees' perception of the organisation's readiness to deal with external demands),

- employment equity (the implementation and fairness of employment equity),

- job satisfaction (employees' general satisfaction),

- factors of importance (why employees come to the company and factors that will influence their decisions to stay with the company).

While assessing the perception of the organization by an employee, we took into account those dimensions that may affect the process of shaping ecological sensitivity. The climatic dimensions identified as the most relevant in this study include commitment, interpersonal communication, satisfaction, reward system, training and development, trust, and fair practices.

\section{Method}

\subsection{Participants and Procedure}

The participants in the empirical data collection were 88 extramural graduate students of a possible 132 employees working for a large, textile manufacturing company. Employees 
voluntarily filled out the questionnaire during class. No inducements were offered to encourage participation. The overall response rate was $93.6 \%$.

The respondents represented middle and low job levels in the organisation, middle management and professionals (11,6\%), junior management and technical (33,5\%), skilled $(39,2 \%)$ and semi-skilled $(15,7 \%)$.

Most respondents $(88,4 \%)$ were between 21 and 30 years of age; $65,8 \%$ had one year but less than five years' work in this comapny; $31,7 \%$ were female while $68,3 \%$ were man.

Education ranged from a high school diploma to a bachelor's degree.

\subsection{Measures and Procedure}

All climate measures were Likert-type scales with responses from 1 (strongly disagree) to 5 (strongly agree).

The research questionnaire contained 38 questions representing 7 analyzed indicators.

The employees received a survey from the researcher during classes at the university. They were informed of the confidentiality and anonymity of their responses. When they had filled out the questionnaire, they returned it in an unmarked envelope. Data were collected in March 2018.

Each indicator was based on several questions. An example from the Commitment scale is "I am strongly associated with the organization." High scores indicate greater commitment. Cronbach's alpha was .71. From Communication is "I can express my opinions freely without fear of punishment" or "The objectives of the organization are communicated to all employees regardless of position". High scores indicate better communication process.

An item from the five-item Satisfaction scale is "Overall, I am satisfied with my role in the organization" or "My job satisfaction in the organization has increased since employment". High scores indicate greater satisfaction. Cronbach's alpha was .66. An example from Reward System is "The salary is competitive with similar organizations". For Training and Development dimention is e.g." The organization provides appropriate training and professional development opportunities". For Trust, a high score indicates greater trust in one's boss. A sample items from the five-item

Trust scale are "Generally, I support decisions made by leaders" or "Overall, I trust the management of the company." Fair Practices was measured using the same five-item Likert scale. A simple items are "Men and women are treated equally at work" or "There are positive relationships in the organization between employees from different age groups". High scores indicate higher evaluation of the practices used in the organization.

\section{Results}

All indicators showed a high level of employee satisfaction. And so the employees regarded the process of communication in the organization as good at $60 \%$; training system $66 \%$ of respondents rated well; $46 \%$ of employees consider the pay system as adequate, with $24 \%$ having a different opinion. The practices applied in the organization in relation to women and older people were rated satisfactory $(82 \%)$.

Detailed percentages of these indicators are included in the appendix.

At this point, we only show indicators that we think are most important when trying to change organizational behavior and attitudes of employees. 


\subsection{Engagement}

Fig. 1. shows the distribution of responses regarding the issue of employee commitment in organization development. Following that analysis, it can be observed that their relationship to the company is positive. Only $19 \%$ of respondents believe that the level of commitment is low, while $\mathbf{5 5 \%}$ feel strongly related to the organization. This indicator is also the answer to the question about the desire to stay or leave the organization in the near future.

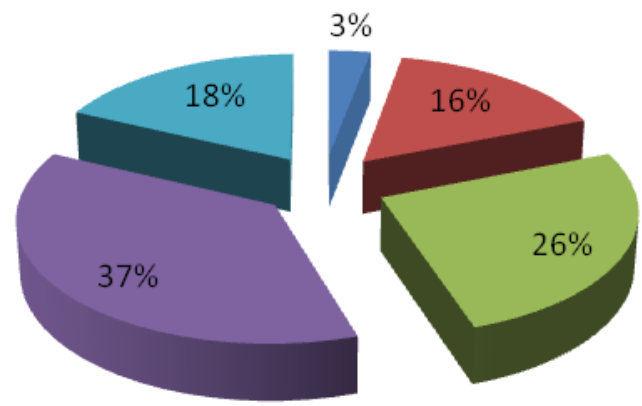

- Strongly Disagree

- Disagree

Neither Agree/ Disagree

Agree

Strongly Agree

Fig. 1. Percentage distribution of employee engagement.

\subsection{Trust}

For the organization overall, trust is correlated with all attitudes, as predicted. In the presence of the other four organizational climate variables, trust predicts both affective commitment and intent to leave. Despite the constant changing in and out of the organization, employees may believe that they can commit to and stay with the organization as long as their current leaders can be trusted. When it comes to job satisfaction, employees often do not perceive trust as affecting the overall convenience or pleasant nature of their work, but such correlation exists [22]. In the surveyed organization, the level of trust among staff is high and reaches $47 \%$. Only $21 \%$ believe that trust is at a low level. 


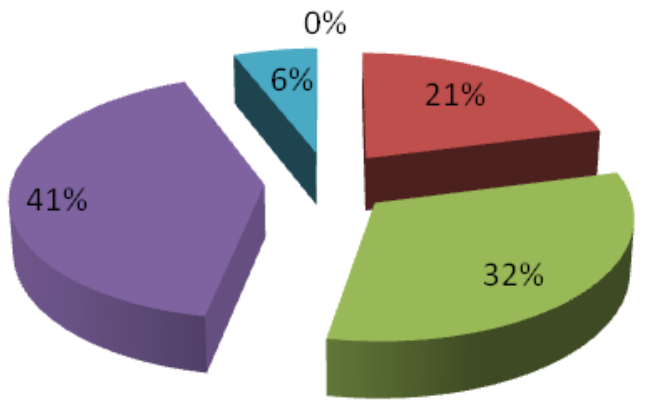

\author{
- Strongly Disagree \\ - Disagree \\ Neither Agree/ Disagree \\ agree
}

- Strongly Agree

Fig. 2. Percentage distribution of employee trust.

\subsection{Satisfaction}

General job satisfaction in the surveyed organization was high $(60 \%$ of respondents rated it as well, $40 \%$ considered it different.

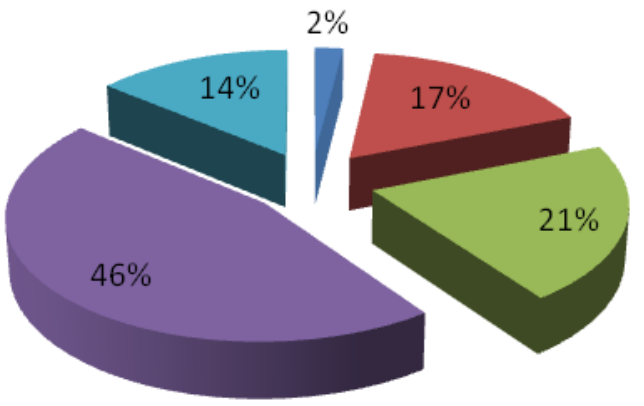

— Strongly Disagree

- Disagree

Neither Agree/ Disagree

agree

- Strongly Agree

Fig. 3. Percentage distribution of employee satisfaction. 


\section{Conclusions}

The data provided a description of a young, educated and trained work force which received moderate levels of financial remuneration. The general picture emerging out of these findings indicate that overall a favorable climate exists in the organization. The organization has a group of professionals who work to increase the organization's benefits and meet their professional satisfaction.

The management shows transparency in decision making and shares information across levels. They also believe in having a participative approach to decision making. There is enough autonomy to perform one's job. Also, the organization offers enough scope for personal and professional growth. The leadership of the organization is approachable and is sensitive to the needs of the employees.

Referring to the concept of sustainable development must be remembered that one of the essential conditions for its implementation is to increase the organizational activities for the benefit of the surrounding environment. This often involves convincing others of the rightness of such solutions, even at the expense of material benefits. However, this is possible primarily in the situation of a high level of mutual trust and a sense of belonging to the community.

The organizational climate can become conducive to develop potential and competencies of the employees and provide opportunities for fulfillment. There is a need to strengthen the role of management in the organization under study, which should feel responsible for building a positive, motivational work culture, which would ensure optimal use of the team members' capabilities leading to self-assessment and organizational efficiency.

These are the features of a good organizational climate. Only employees who feel well in the organization can meet the challenges posed by the clash of organizational and group goals with general social goals. In a good climate, difficult decisions are easier to make.

The next stage of research should be to examine to what extent this positive organizational climate favors adjusting the organization to the concept of sustainable development.

\section{References}

1. E. Giovannini, M. Linster, Measuring sustainable development. Achievements and challenges (OECD, 2005)

2. P. Dobrzański, Wzrost zrównoważony a ochrona środowiska. Podstawowe aspekty polityki gospodarczej, Prace Naukowe Wydziału Prawa, Administracji i Ekonomii Uniwersytetu Wrocławskiego, 8, 25-33 (2011)

3. J. Kronenberg, T. Bergier (red.), Wyzwania zrównoważonego rozwoju w Polsce (Fundacja Sendzimira, Kraków, 2010)

4. D.R. Denison, What is the difference between organizational culture and organizational climate? A native's point of view on a decade of paradigm wars. Acad. of Manag. Rev., 21(3), 619-654 (1996)

5. B. Schneider, The psychological life of organisations, in Handbook of organisational culture and climate, edited by NM Ashkanasy, (CPM Wilderam \& MF Peterson, London: Sage, 2000)

6. G. Litwin \& R. Stringer, Motivation and organizational Climate (Boston HUP, 1968)

7. R. Field, \& M. Abelson, Climate: Reconceptualization and proposed model. H. Rel., 35 (3), 181-201 (1982) 
8. J.W. Wiley, S.M. Brooks, The high performance organisational climate. How workers describe top-performing units, in Handbook of organisational culture and climate, edited by N.M. Ashkanasy (C.P.M. Wilderam \& M.F. Peterson, London: Sage, 2000)

9. L.R. James, C.C. Choi, C.E. Ko, P. McNeil, M.K. Minton, M.A. Wright, K. Kim, Organizational and psychological climate: A review of theory and research. Eur. J. W. \& Org. Psych., 17(1), 5-32 (2008)

10. G. Forehand, B. Von Gilmer, Environmental variations in studies of organizational behaviour. Psych. B., 62, 362-381 (1964)

11. R. Guion, A note on organisational climate. Org. B. \& Hum. Perform., 9,120-125 (1973)

12. A. Furnham, B. Gunter, Corporate assessment. Auditing a company's personality (London: Routledge, 1993)

13. A.E. Reichers, B. Schneider, Climate and culture: An evolution of constructs. In B. Schneider (Ed.) Organizational Climate and Culture (San Francisco: Jossey-Bass, 1990)

14. W.F. Joyce, J.W. Slocum, Collective climate: Agreement as a basis for defining aggregate climates in organizations. Academy of Man. J., 27(4), 721-742 (1984)

15. L. James, A. Jones, Organizational Climate: A review of theory and research. Psych. B., 12, 1096-1112 (1974)

16. F. Cilliers, S. Kossuth, The relationship between organisational climate and salutogenic functioning. Sth. Afr. J. of Indust. Psych., 28 (1), 8-13 (2002)

17. N. Martins, A model for managing trust. Int. J. of Man., 23 (8), 754 - 769 (2002)

18. N. Martins, H. von der Ohe, Trust as a factor in determining how to attract, motivate and retain talent. Sth. Afr. J. of Indust. Psych., 28 (4), 49-57 (2002)

19. A. Jones, L. James, Psychological climate: Dimensions and relationships of individual and aggregated work environment perception. Org. B. \& Hum. Perform., 23, 201-250 (1979)

20. C.M. Tustin, A consensus approach to the measurement of organizational climate. J. of Indust. Psych., 19 (1):1-4 (1993)

21. E.C. Martins, N. Martins, Organisational Surveys as a tool for change. Part two: A case study. HR Future, 1 (4): 46-49 (2001)

22. S.W. Lester, H.H. Brower, In the eyes of the beholder: The relationship between subordinates' felt trustworthiness and their work attitudes and behaviors. J. of Lead. and Org. Stud., 10, 17-33 (2003) 


\title{
Appendix
}

\section{Communication}

This indicator focus the clearness of upward and downward communication and the relationship between subordinate and supervisor.

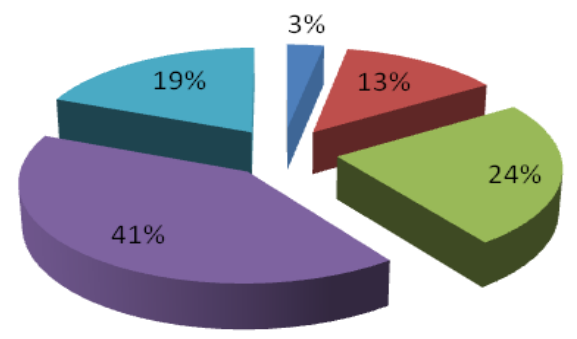

\author{
- Strongly Disagree \\ - Disagree \\ Neither Agree/ Disagree \\ - Agree \\ Strongly Agree
}

Fig. 4. Percentage distribution of employee rated Process of Communication.

\section{Reward system}

This indicator focuses on employees feeling that awards are granted fairly and in exchange for good results.

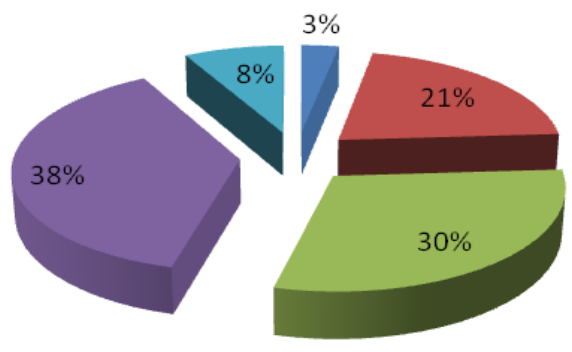

$$
\begin{aligned}
& \text { Strongly Disagree } \\
& \text { Disagree } \\
& \text { Neither Agree/ Disagree } \\
& \text { Agree } \\
& \text { Strongly Agree }
\end{aligned}
$$

Fig. 5. Percentage distribution of employee evaluation regarding reward system. 


\title{
Treaining \& Developing
}

This indicator focuses on issues related to the possibilities of building a career in the organization and acquiring new skills.

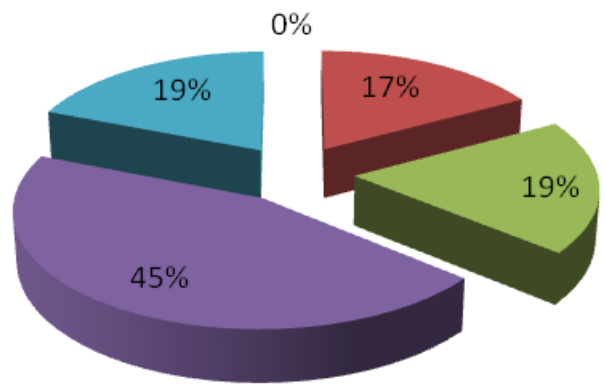

— Strongly Disagree

- Disagree

Neither Agree/ Disagree

- Agree

- Strongly Agree

Fig. 6. Percentage distribution of employee evaluation regarding training and development.

\section{Fair practices}

This indicator identifies employee observations regarding such issues as: equal treatment of employees irrespective of their gender or age.

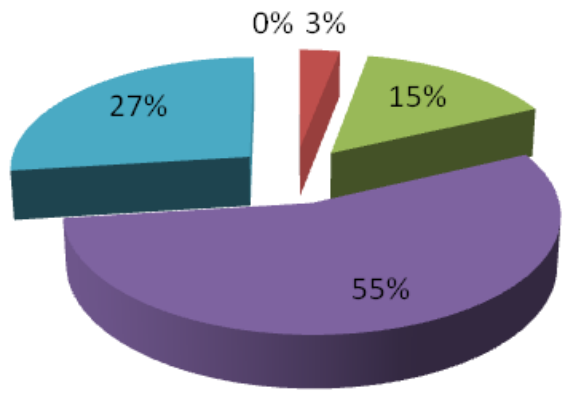

\author{
n Strongly Disagree \\ n Disagree \\ neither Agree/ Disagree \\ - Agree \\ a Strongly Agree
}

Fig. 7. Percentage distribution of employee observations on fair practices. 